\title{
BLUE GALAXIES IN DISTANT CLUSTERS
}

\author{
JABLONKA P. \& ALLOIN D. \\ D.A.E.C, Observatoire de Paris, France
}

We analyzed - in terms of age and metallicity - the stellar content of blue galaxies in 3 distant clusters at $z \sim 0.3$. We found that they contain a more metal-rich population than nearby late-type spirals.

TABLE 1. Population synthesis results : contributions in $\%$ of the different generations of stars (Age, $\left[\mathrm{Z} / \mathrm{Z}_{\odot}\right]$ ) to the total galaxy flux

A typical nearby late-type spiral galaxy

\begin{tabular}{|c|c|c|c|c|c|c|c|c|c|}
\hline & $\%$ & HIIR & $10^{7}$ & $510^{7}$ & $10^{8}$ & $510^{8}$ & $10^{9}$ & $510^{9}$ & $>10^{10}$ \\
\hline \multirow{7}{*}[\mathrm{Z}/\mathbf{Z}_{\odot}]{} & +0.6 & \multirow{7}{*}{1.56} & \multirow{7}{*}{2.90} & \multirow{7}{*}{3.49} & \multirow{7}{*}{3.63} & \multirow{7}{*}{29.45} & \multirow{7}{*}{5.74} & \multirow{7}{*}{6.55} & 3.57 \\
\hline & +0.3 & & & & & & & & 3.98 \\
\hline & 0.0 & & & & & & & & 4.71 \\
\hline & -0.5 & & & & & & & & 8.33 \\
\hline & -1.0 & & & & & & & & 10.50 \\
\hline & -1.5 & & & & & & & & 8.13 \\
\hline & -2.0 & & & & & & & & 7.48 \\
\hline
\end{tabular}

A group of blue galaxies in the cluster AC 114

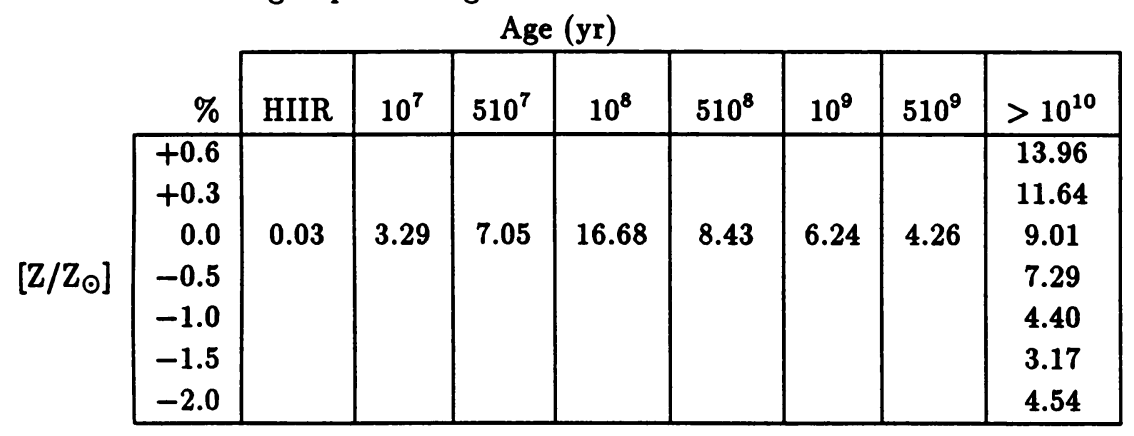

